Decision Making,

\section{Countermanding Oculomotor} Models

\author{
Vassilis Cutsuridis \\ School of Computer Science, \\ University of Lincoln, Lincoln, UK
}

\section{Definition}

The countermanding oculomotor task or stopsignal task (see Fig. 1) requires participants to make a saccade to a GO stimulus (no-stop-signal trial) but stop the saccade when a STOP signal is presented (stop-signal trial). Participants' ability to inhibit the response depends on the interval between the GO and STOP signals, often referred to as the stop-signal delay (SSD). When the GO signal has a small head start relative to the STOP signal, then subjects succeed at inhibiting their responses. As the head start grows, subjects often fail to inhibit the response.

\section{Detailed Description}

\section{The Countermanding Oculomotor Task}

The countermanding saccade task (Fig. 1) is a response inhibition paradigm, in which participants are required to make a saccade as quickly as possible to a GO signal (no-stop-signal trial). In few trials a STOP signal is presented, and the response must be stopped (stop-signal trial). There are two possible behavioral outcomes in this paradigm: (1) Participants fail to inhibit their response producing a signal-respond trial with a signal-respond reaction time (RT) and (2) participants inhibit their response producing a signalinhibit or cancelled trial. Participants' ability to inhibit their response depends on the interval between the GO and STOP signal presentation, often referred as the stop-signal delay (SSD) (see Fig. 2a). When SSD is short, subjects often succeed at inhibiting; as SSD grows, subjects often fail to inhibit the response. When subjects fail to stop on stop-signal trials, their responses tend to be faster than on trials without a stop signal. An important aspect of the countermanding task is to determine the stop-signal reaction time (SSRT), the length of time required to cancel the saccade being programmed and maintain fixation on the central fixation spot. Because the duration of this inhibitory process is not explicit in the behavioral data, then an estimate of SSRT is calculated as the mean reaction time when no-stop signal is given minus the delay for which inhibition occurs on $50 \%$ number of trials (Hanes and Carpenter 1999). The probability of inhibiting/probability of responding as a function of SSD is referred as 


\section{Stop trials}

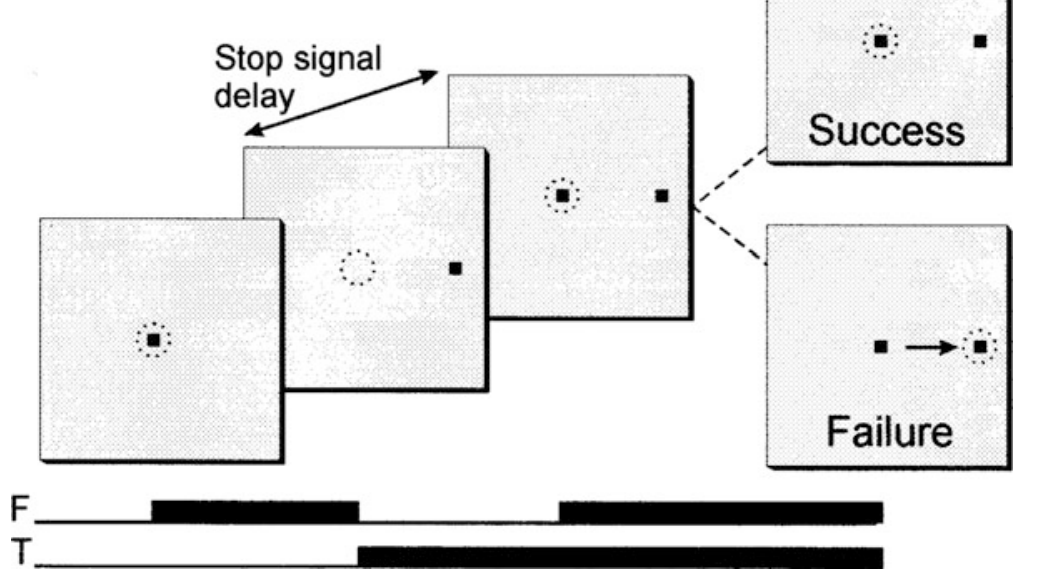

Decision Making, Countermanding Oculomotor Models, Fig. 1 Basic design of the countermanding task. (Reproduced with permission from Hanes and Carpenter (1999), Fig. 1, p. 2778, Copyright (C) 1999, Elsevier). Typically a participant fixates on a central fixation spot $(\mathrm{F})$ for a variable interval. Once it disappears, a visual target $(\mathrm{T})$ simultaneously appears in the periphery.
After a delay in some trials, the fixation spot may reappear (stop-signal delay (SSD)) during which subjects are instructed to withhold the movement. Subjects sometimes successfully countermand the saccades, and sometimes they do not. The dotted circle indicates the focus of gaze at each interval, and the arrow indicates the saccade

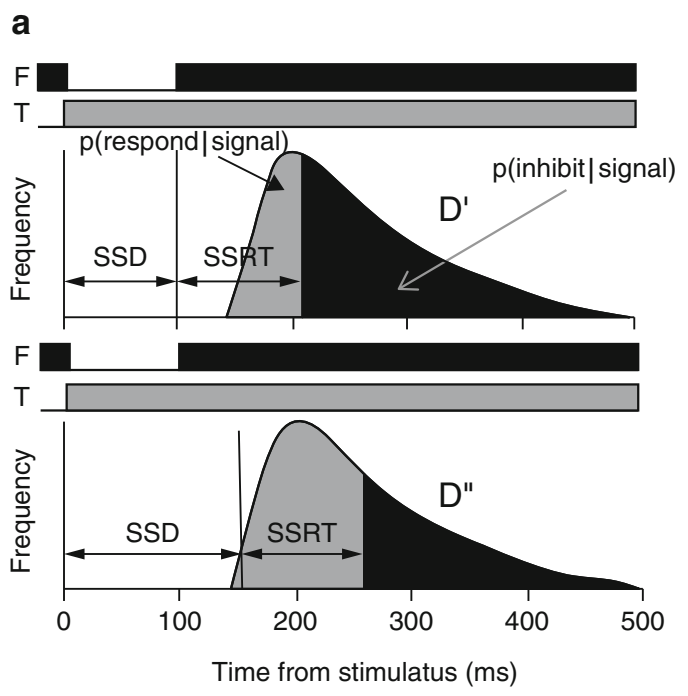

Decision Making, Countermanding Oculomotor Models, Fig. 2 (a) Schematic indicating how the probability of responding [p(respond|signal)] and the probability of inhibiting [p(inhibit|signal)] depend on GO- RT, SSD, and SSRT distributions. (Reproduced with minor changes from Boucher et al. (2007), Fig. 1D, p. 377, Copyright (C)

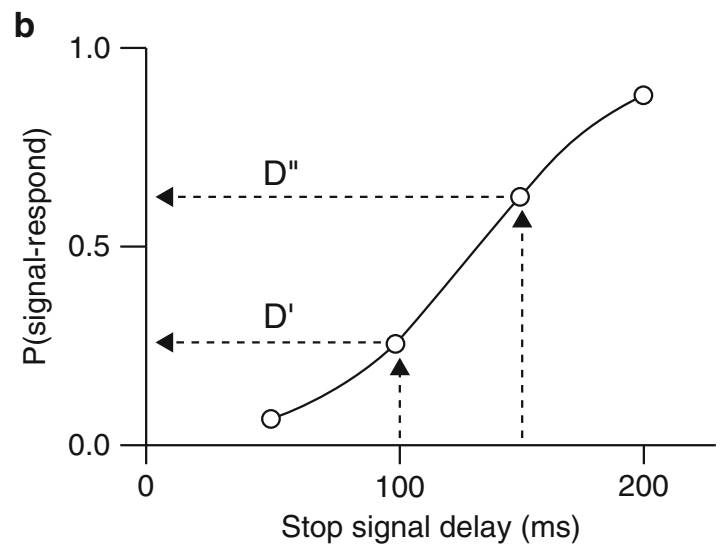

2007 American Psychological Association). (b) Plot of inhibition function as function of SSD. D' and D" indicate the proportion of signal-respond trials at SSDs of $100 \mathrm{~ms}$ and $150 \mathrm{~ms}$, respectively. (Reproduced with from Boucher et al. (2007), Fig. 1C, p. 377, Copyright (C) 2007 American Psychological Association) 
the inhibition function (see Fig. $2 \mathrm{~b}$ for the probability of responding as a function of SSD).

\section{Human Performance in the Countermanding Oculomotor Task}

Early countermanding or stop-signal experiments involved manual responses to visual GO signals and visual/auditory STOP signals (Logan and Cowan 1984). The first countermanding oculomotor task was introduced by Hanes and Carpenter (1999). In this task, participants were asked initially to fixate on a central stimulus. As soon as the central (fixation) stimulus disappeared, a peripheral (target) stimulus appeared either to the left or right peripheral visual field, and the participants had to make a saccadic eye movement toward it. On some trials, the fixation stimulus reappeared, acting as a STOP signal, instructing the participant that the saccade should be inhibited and instead to hold his/her gaze on the fixation stimulus. Mean saccade latencies on the GO trials were reported to be $200-300 \mathrm{~ms}$ and were faster with a higher luminance contrast visual stimulus. On the other hand, SSRTs ranged from 125 to $145 \mathrm{~ms}$ but did not vary with target luminance. Schall and Thompson (1999) suggested that the short STOP signal latency may be due to the STOP signal being presented centrally to the fovea. Asrress and Carpenter (2001) tested the effectiveness of central and peripheral visual stimuli in the stop-signal response. They reported that central and peripheral visual stop cues produced the same SSRTs. However, when both cues were used, then the SSRTs were shortened, suggesting that the central and peripheral stop signals have independent inputs to the stopping process.

Other experiments examined the effects of other sensory modalities in response inhibition and reported that the SSRTs were slightly longer when an auditory or a tactile instead of a visual stimulus was used as a STOP signal (Armstrong and Munoz 2003; Morein-Zamir and Kingstone 2006; Akerfelt et al. 2006; Cabel et al. 2000). Subsequent experiments have reported that human subjects respond faster and with greater accuracy to stimuli that are brighter, louder, and associated with larger reward or have larger probability of appearance, than to neutral stimuli (Wattiez et al. 2016).

Recent experiments investigated how saccade cancellation is influenced by the fixation disengagement (Stevenson et al. 2009). Human participants performed countermanding experiments that required them to try to cancel an impending saccade in the presence of an imperative visual STOP signal, across different fixation conditions. Stop signal reaction times were $\sim 40 \mathrm{~ms}$ shorter on trials with a $200 \mathrm{~ms}$ gap between fixation point removal and target presentation compared with when the fixation point remained illuminated. Investigators concluded that the reduction in SSRTs were primarily due to removal of a foveal fixation point (as opposed to a generalized warning effect) and persisted with an auditory stop signal that controlled for potential differences in stop signal saliency across different fixation conditions.

\section{Countermanding Oculomotor Performance in Disorders}

Countermanding performance has also been investigated in many neurological and psychiatric disorders including attention deficit hyperactivity disorder (ADHD; Armstrong and Munoz 2003; Hanisch et al. 2006), schizophrenia (Thakkar et al. 2011, 2015), bipolar disorder (Thakkar et al. 2015), and Parkinson's disease (Farooqui et al. 2011).

In particular, patients with ADHD involved in a countermanding saccade task (Armstrong and Munoz 2003) made more impulsive eye movements than age-matched controls. Furthermore, ADHD participants were faster to respond to a target, but they were more likely to fail to countermand an eye movement on STOP trials (Armstrong and Munoz 2003). SSRTs of adult ADHD patients were reported to be longer in a saccadic countermanding task, particularly with an auditory or peripheral visual stop signal (Armstrong and Munoz 2003). Slower SSRTs were also observed in children diagnosed with ADHD (Hanisch et al. 2006).

Similarly, patients suffering with schizophrenia (Thakkar et al. 2011) were associated with increased latency to inhibit a planned saccade. 
Longer SSRTs were found in patients, despite patients having equal sensitivity to the stop signal and similar latencies to initiate a saccade. Their SSRTs were correlated with increased negative symptoms and poorer occupational functioning, indicating the clinical relevance of these findings. Patients made appropriate RT adjustments after errors but slowed down significantly more than control subjects after correctly inhibited saccades. Subsequent experiments from the same group tested the countermanding performance of schizophrenia patients in a double-step task (Thakkar et al. 2015). In this task, participants were required to make a saccade to a visual target. Infrequently, the target jumped to a new location, and participants were instructed to rapidly inhibit and change their response. Patients had poorer efficiency of inhibition, indexed by longer TSRT (target step reaction time). An impairment in response execution was also observed when patients were required to redirect gaze to a new location.

\section{Non-human Primate Performance in the Countermanding Oculomotor Task}

The primate brain circuits involved in the countermanding oculomotor task are complex, involving many brain areas (for reviews see Schall and Godlove (2012)). Neurons in the frontal eye field (FEF), supplementary eye field (SEF), lateral intraparietal area (LIP), pre-supplementary motor area (preSMA), and subthalamic nucleus (STN), and superior colliculus have been described as movement-related in the saccade countermanding task. However, neuronal recordings from SEF, LIP, preSMA, and STN have produced conflicting results (for more details see Stuphorn et al. 2000; Scangos and Stuphorn 2010; Isoda and Hikosaka 2007, 2008). The two brain areas that are the most studied and have produced the most consistent results in response inhibition in the countermanding task are the FEF and SC.

FEF is an area in the dorsolateral prefrontal cortex of macaque monkeys where neurons respond to visual stimuli but also are involved in the production of saccadic eye movements
(Bruce et al. 1985; Hanes and Schall 1996; Sommer and Wurtz 2000; Segraves and Goldberg 1987). The FEF movement-related neurons have been shown to discharge before and during saccades (Bruce and Goldberg 1985; Hanes and Schall 1996) and innervate other movementrelated neurons in SC and the brainstem (Segraves and Goldberg 1987; Sommer and Wurtz 2000; Segraves 1992). Other FEF and SC neurons have been shown to discharge during fixation but suppress their activities during saccades. These fixation cells are critical for controlling saccade initiation. Electrical stimulation of SC fixation cells can interrupt saccades in monkeys (Gandhi and Keller 1999), and their deactivation results in excessive saccade initiation (Munoz and Wurtz 1993). Two experimental studies have described the activities of movementrelated and fixation neurons in FEF and SC in macaque monkeys performing a saccade stop signal task (Hanes et al. 1998; Pare and Hanes 2003). Once the GO signal was given (target appeared), then movement- related neuronal activity in both areas grew toward a threshold. In trials where no STOP signal was presented, these activities continued to grow (see Fig. 3a left). The activities of corresponding fixation neurons were decreased (see Fig. 3a right). If a STOP signal was presented (cancelled trial), then the movement-related activities were inhibited (see Fig. 3a left) and the fixation cells generated rapid bursts (see Fig. 3a right). This activation reciprocity of movementrelated and fixation cells naturally reinforces the idea that they share a mutually inhibitory relationship.

A similar inhibitory relationship exists between fixation and saccade neurons in macaque monkeys performing the antisaccade task (Everling et al. 1999; Everling and Munoz 2000). Fixation cells are tonically active when subjects are fixating, and they pause their activities when a saccade is executed. Saccade neurons, on the other hand, discharge when a saccade is initiated but remain silent during fixation. Two populations of saccade neurons have 


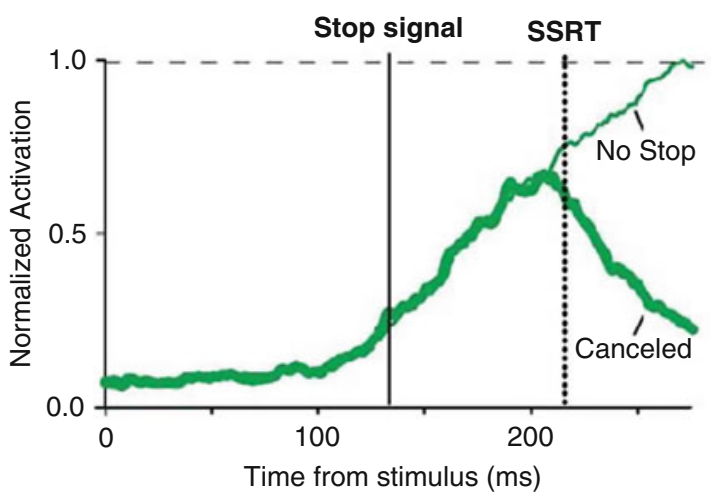

Decision Making, Countermanding Oculomotor Models, Fig. 3 Normalized activity of FEF gaze-shifting (left) and gaze-holding (right) neurons. (Reproduced with permission from Schall and Godlove (2012), Fig. 2, p. 1014, Copyright (C), Elsevier). Thick green and red lines represent the activities of cancelled FEF gaze-shifting and gaze-holding neurons, respectively. Thin green and red

been recorded in SC: buildup and burst cells (Munoz and Wurtz 1993, 1995a, b).

\section{Computational Models of Countermanding Oculomotor Performance}

Over the years many mathematical and computational models of countermanding oculomotor performance have been proposed. Some of these models provide explicit descriptions of the mental processes that are tightly linked to countermanding behavior, and others focus on the neurons, networks, or brain regions involved in the countermanding task. A direct comparison of the performance of these various computational models in the countermanding task can be found in Table 1.

\section{Independent Horse-Race Model}

The oldest and most successful model of the countermanding task is the "independent horse-race model" (Fig. 4; Logan and Cowan 1984). The model is intuitively simple consisting of two independent accumulators, a GO process and a STOP process, which race each other till a predefined threshold is reached by one process.

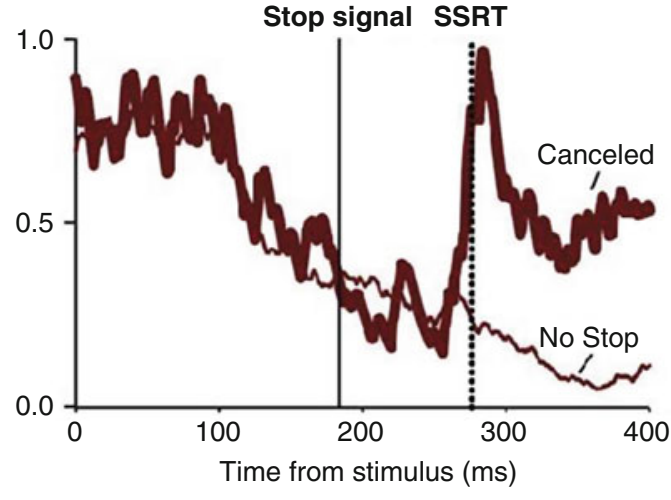

lines represent the activities of non-cancelled FEF gazeshifting and gaze-holding neurons, respectively. Presentation of the stop signal is indicated by the solid vertical line. The time needed to cancel the planned movement - stop signal reaction time (SSRT) - is indicated by the dashed vertical line

If the GO process, initiated at GO stimulus onset, reaches the threshold first, then stimulus response is generated, and the trial ends; if the STOP process, initiated at the STOP stimulus onset, reaches the threshold first, then the subject stops, and the trial ends. The STOP process wins the race if SSRT + SSD is less than the GO-RT. Then, the response is inhibited and a signal-inhibit trial takes place. If the SSRT + SSD is greater than the GO-RT, then the GO process wins, the response is executed, and a signal-respond trial occurs. Because the GO-RT and SSRT are assumed in the model to be independent random variables drawn from their response time distribution, then the outcome of the race includes a random component. Increases in SSD favor the GO process and so the STOP process wins less often. Thus, the probability of inhibiting the response decreases, and the probability of responding increases. Such a relationship reproduces the experimentally observed inhibition function. The "independent race model" explains further why the responses in the stop-signal trials are faster than the no-stop-signal ones and how they change in relation to the SSD. When the SSD is short, only the fastest GO-RTs are faster than $\mathrm{SSRT}+\mathrm{SSD}$, so signal-respond RT is very short, reflecting the lower tail of the GO-RT distribution. 
Decision Making, Countermanding Oculomotor Models, Table 1 Comparison of performance of computational models in the countermanding paradigm.
(Reproduced with permission from Cutsuridis (2017), Table 1, p. 9, Copyright (C), Royal Society Publishing)

\begin{tabular}{|c|c|c|c|c|c|c|}
\hline \multirow[t]{3}{*}{ Modelling study } & \multicolumn{2}{|c|}{ Behavioral data } & \multicolumn{4}{|c|}{ Neurophysiology data } \\
\hline & \multirow[t]{2}{*}{$\begin{array}{l}\text { Inhibition } \\
\text { function }\end{array}$} & \multirow[t]{2}{*}{$\begin{array}{l}\text { Cumulative } \\
\text { reaction time } \\
\text { distributions }\end{array}$} & \multicolumn{2}{|c|}{$\begin{array}{l}\text { Movement } \\
\text { neuron profile }\end{array}$} & \multicolumn{2}{|c|}{$\begin{array}{l}\text { Fixation neuron } \\
\text { profile }\end{array}$} \\
\hline & & & $\begin{array}{l}\text { No- } \\
\text { stop }\end{array}$ & Cancelled & $\begin{array}{l}\text { No- } \\
\text { stop }\end{array}$ & Cancelled \\
\hline $\begin{array}{l}\text { Independent race model (Logan and } \\
\text { Cowan 1984) }\end{array}$ & $\sqrt{ }$ & $\sqrt{ }$ & & & & \\
\hline $\begin{array}{l}\text { Countermanding LATER model } \\
\text { (Hanes and Carpenter 1999) }\end{array}$ & $\sqrt{ }$ & $\sqrt{ }$ & & & & \\
\hline $\begin{array}{l}\text { Interactive race model (Boucher et al. } \\
\text { 2007) }\end{array}$ & $\sqrt{ }$ & $\sqrt{ }$ & $\sqrt{ }$ & $\sqrt{ }$ & $\sqrt{ }$ & \\
\hline $\begin{array}{l}\text { Augmented interactive race with pre- } \\
\text { target model (Wong-Lin et al. 2010) }\end{array}$ & $\sqrt{ }$ & $\sqrt{ }$ & $\sqrt{ }$ & $\sqrt{ }$ & $\sqrt{ }$ & \\
\hline $\begin{array}{l}\text { Spiking neural model with top-down } \\
\text { control (Lo et al. 2009) }\end{array}$ & $\sqrt{ }$ & $\sqrt{ }$ & $\sqrt{ }$ & $\sqrt{ }$ & $\sqrt{ }$ & \\
\hline $\begin{array}{l}\text { Cancellable rise-to- threshold model } \\
\text { (Salinas and Stanford 2013) }\end{array}$ & $\sqrt{ }$ & $\sqrt{ }$ & & & & \\
\hline $\begin{array}{l}\text { Blocked-input } 1.0 \text { model (Logan et al. } \\
\text { 2015) }\end{array}$ & $\sqrt{ }$ & $\sqrt{ }$ & $\sqrt{ }$ & $\sqrt{ }$ & $\sqrt{ }$ & \\
\hline $\begin{array}{l}\text { Blocked-input } 2.0 \text { model (Logan et al. } \\
2015 \text { ) }\end{array}$ & $\sqrt{ }$ & $\sqrt{ }$ & $\sqrt{ }$ & $\sqrt{ }$ & $\sqrt{ }$ & \\
\hline $\begin{array}{l}\text { Boosted-fixation } 1.0 \text { model (Logan } \\
\text { et al. 2015) }\end{array}$ & $\sqrt{ }$ & $\sqrt{ }$ & $\sqrt{ }$ & $\sqrt{ }$ & $\sqrt{ }$ & \\
\hline
\end{tabular}

As the SSD increases, more GO-RTs are fast enough to win the race, so signal-respond RT increases. If the SSD is long enough, all GO-RTs will win the race, and signal-respond RT will approach no-stop-signal RT. The model has been successfully able to quantitatively simulate the inhibition function as a function of SSD and the SSRT distributions across age, patient groups, and experimental conditions. The model did not though consider the underlying neural processes. Furthermore, recent experimental evidence has ruled against the independent race of the GO and STOP processes (Montagnini and Chelazzi 2009).

\section{Countermanding LATER Model}

A model similar to Logan and Cowan's (1984) "independent horse-race model" is the countermanding LATER model of Hanes and Carpenter (1999) (see Fig. 5). The countermanding LATER model consists of two independent LATER units, a GO unit and a
STOP unit, racing each other to a threshold. The rate of rise of each LATER unit's activity takes values from two normal distributions with different means and standard deviations. In the model, as in the experiment, the GO unit is activated first, followed by activation of the STOP unit, which in turn inhibits the GO unit. If the GO unit reaches the threshold before the STOP unit, then a GO response is generated. If the STOP unit reaches the threshold before the GO unit, then a No-GO response is generated. If the GO unit activity reaches threshold first, then a GO response is generated. The model is able to simulate accurately the RT distribution and inhibition function as a function of SSD. However, it does not attempt to provide any insights to the neural mechanisms of stopping.

\section{Interactive Race Model}

The "interactive race model" (see Fig. 6) was introduced (Boucher et al. 2007) as an alternative 


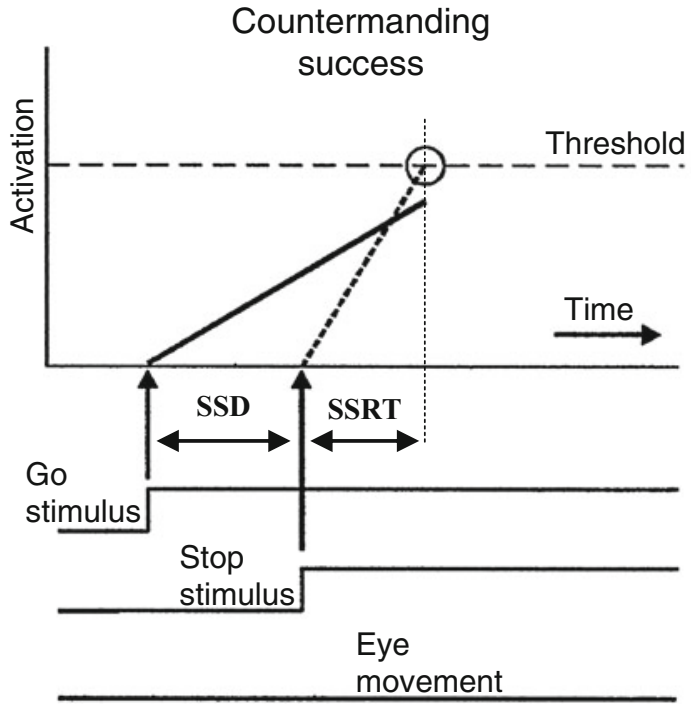

Decision Making, Countermanding Oculomotor Models, Fig. 4 Basic schematic of the independent horse-race model of countermanding performance. Two independent processes race toward a threshold, where one process is initiated by a GO signal, while the other process by a STOP signal after a variable stop signal delay (SSD). If the GO process crosses the threshold first, it wins the race and a non-cancelled response is made. If the STOP

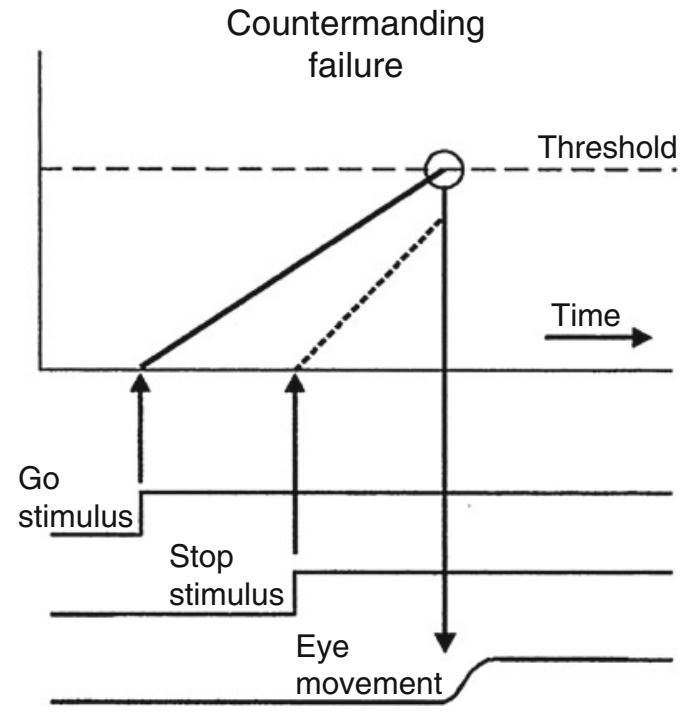

process crosses the threshold first, it wins the race, and the response is inhibited. The STOP signal response time (SSRT) is the time between STOP signal onset and the point where the STOP process crosses the threshold to countermand the response. (Reproduced with permission from Hanes and Carpenter (1999), Fig. 4, p. 2782, Copyright (C), 1999, Elsevier)

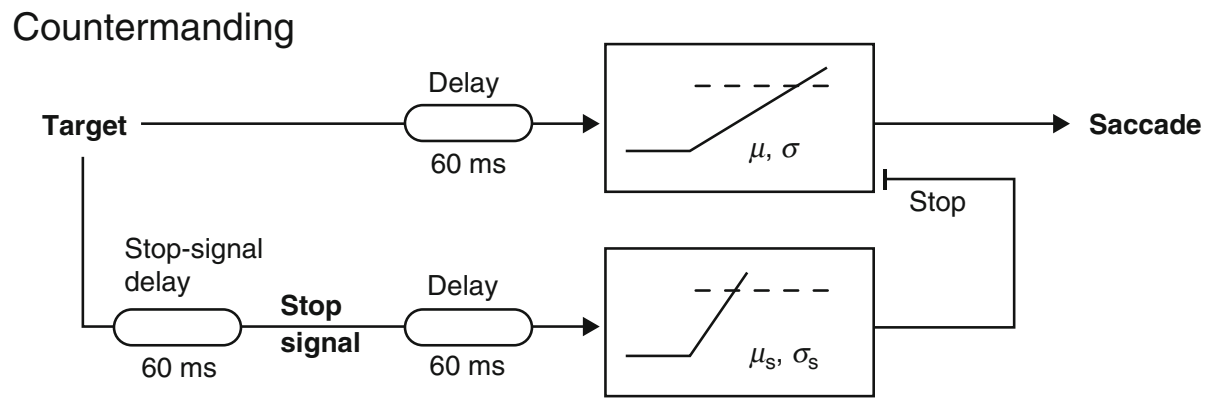

Decision Making, Countermanding Oculomotor Models, Fig. 5 Countermanding LATER model. (Reproduced with permission from Noorani (2014), Fig. 4, p. 3, Copyright (C), Frontiers publishing company). A GO unit competes with a STOP unit, and the winner of

to the previous race models in order to suggest how neural circuitry could give rise to the observed behaviors. To this end, the authors (Boucher et al. 2007) quantitatively simulated the behavior of the countermanding task and specified the neural underpinnings of stopping. They proposed that lateral inhibition between the competition determines the outcome. In some trials, the GO unit reaches threshold even in the presence of the STOP unit, which failed to stop it (non-cancelled trials). In other trials, the STOP unit is faster than the GO unit, so no response (saccade) is generated (cancelled trials)

competing neural accumulators is the mechanism for stopping. This model assumption was in line with the experimentally observed modulation of neural activity from recurrently inhibited neurons in SC and FEF, two brain areas directly involved in saccadic eye movements (discussed in the previous section; Hanes et al. 1998; Pare 


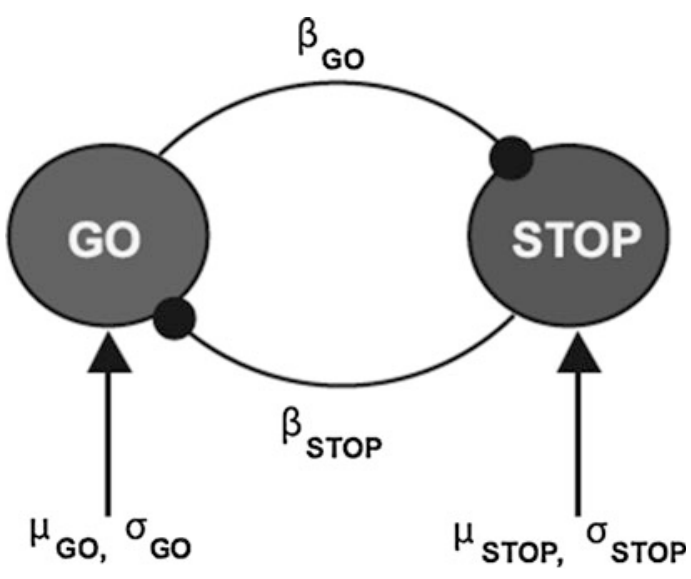

Decision Making, Countermanding Oculomotor Models, Fig. 6 Interactive race model. (Reproduced with permission from Logan et al. (2015), Fig. 9b, p. 49, Copyright (C) 2015 American Psychological Association)

and Hanes 2003). As in the previous models, the interactive model consisted of two accumulators, the GO process and the STOP process. The GO process was modelled as a stochastic accumulator that integrated neural activity over time until it reached a threshold, after which a response was made. Similarly, the STOP process was modelled as a stochastic accumulator that stopped the response by inhibiting the GO activation and preventing it from reaching the threshold. The STOP and GO processes were mutually inhibiting each other, but their strengths were asymmetric with the STOP process inhibiting the GO process more than the GO process inhibited the STOP process. Because in the model the GO and STOP processes proceed independently for most of their duration, the STOP unit inhibited the GO unit strongly only very late in the trial. This produces finishing times that appear independent, as in the independent model. The model has been successful at simulating accurately both behavioral and neurophysiological data including the activation profiles of gaze-responding neurons (movement and fixation cells) in the signal-inhibit and no-stop-signal trials.

\section{Cancellable Rise-to-Threshold Model}

Salinas' and Stanford's (2013) “cancellable riseto-threshold model" is built on the foundation of the compelled saccade task (Shankar et al. 2011), which attempts to separate the contribution of perceptual and motor processing in the countermanding task. As in the interactive race model, programming a saccade involves a process building activity to a threshold. The model assumes that once a stop-stimulus is presented, a perceptual mechanism detects it with a particular speed and reliability. Once the signal is detected, then the movement plan decelerates, and the movement is stopped. The model successfully replicates the experimentally observed countermanding behavior, but it does not attempt to reproduce the recorded neural activity. However, it has been suggested to be profoundly similar to the "interactive race model" and hence matches the earlier model in its predictions (see Bissett (2013) for a critique of the "cancellable rise-to-threshold model").

\section{Augmented Interactive Race with Pre-target Input Model}

Wong-Lin and colleagues (2010) advanced an extension (see Fig. 7) of the "interactive race model" by including an additional pre-target input to account for the experimentally reported high firing rates of fixation neurons (Hanes et al. 1998). They demonstrate that such simulated pre-target fixation neuronal activity reproduces countermanding behavior that maximizes reward rate as a function of SSD, fraction of stop-signal trials, intertrial interval, duration of timeout, and relative reward value. Further, it simulated accurately the neural traces of movement and fixation cells in no-stop and cancelled trials.

\section{Spiking Interactive Race with Top-Down Inhibition Control Model}

Lo and colleagues (2009) introduced an attractorbased model of neural spiking dynamics. The neural network model was multi-modular consisting of a premovement module that controlled inhibition of movements and a control module that provided a top-down inhibitory control over the premovement module. The model replicated the probability of responding and RTs on correct and error trials as well as the patterns of activity observed in SC and FEF (Hanes et al. 1998; Pare and Hanes 2003). The model made new predictions and suggested new experiments. 


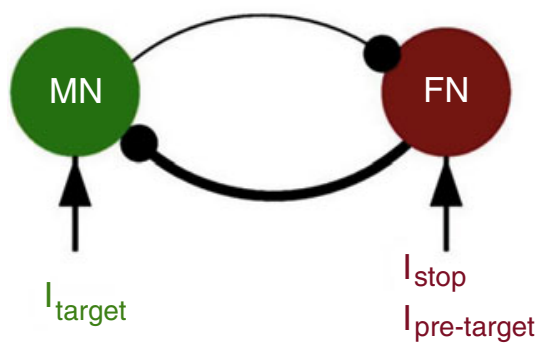

Decision Making, Countermanding Oculomotor Models, Fig. 7 (Left) Augmented interactive race with pre-target input model. (Reproduced with permission from Wong-Lin et al. (2010), Fig. 1A, p. 12, Copyright (C) 2010 Elsevier Science Ltd). Asymmetrical mutual inhibition

Particularly, their model predicted that the neural activities of movement and fixation neurons are negatively correlated earlier in non-cancelled trials than in cancelled trials. It demonstrated that inhibitory control in the countermanding task is due to modulation of the strength of the top-down drive to the movement module. Weaker simulated top- down control resulted in shorter reaction times, more errors, but unchanged SSRTs.

Despite its successes, the model did not incorporate all of the brain circuits involved in control of saccades, omitting areas such as the supplementary frontal eye field (SEF), and anterior cingulate cortex (ACC). Furthermore, the model did not separate the stimulus-driven input and the top-down input to fixation neurons in order to assess their effects on inhibitory control (Asrress and Carpenter 2001).

\section{Other Race Models}

Recently, Logan et al. (2015) introduced new variations of the original interactive race model (Boucher et al. 2007), namely, the "blocked-input 1.0 race model," the "blocked-input 2.0 race model," and the "boosted-fix 1.0 race model" (see Fig. 8). The "blocked-input 1.0 race model" assumed that the STOP unit did not directly inhibit the GO activation, but instead it activated a top-down process that turned off the GO activation and set the mean neural GO activity to zero once it reached the threshold. If the input is blocked early enough, then the GO neural activation did not reach the threshold and the response

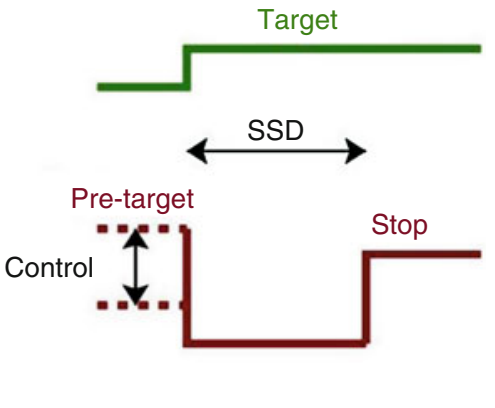

between movement $(\mathrm{MN})$ and fixation $(\mathrm{FN})$ neural units is observed. (Right) Inputs trace to $\mathrm{MN}$ (green) and $\mathrm{FN}$ (red). SSD = stop signal delay. Cognitive control is assumed to vary pre-target $\mathrm{FN}$ input

was inhibited. If the GO activation reached the threshold before its input was blocked, then inhibition failed and the GO response was executed. The "blocked-input 1.0 race model" fits the behavioral data as well as the original interactive model indicating that direct inhibition from the STOP process on the GO process is not needed to account for the countermanding behavior. The "blocked-input 1.0 race model" fitted monkey neurophysiological data better than the original interactive model by predicting growth rates, decay rates, and cancel times that fell within the $95 \%$ confidence intervals of the observed monkey data. The "blocked-input 2.0 race model" was the same as the original interactive model with mutual inhibition between the GO and STOP processes except that it also includes a third independent top-down process that also inhibits the GO signal. Version 2.0 of the "blocked-input race model" produced as good a fit to the behavioral and neurophysiological data as version 1.0 but a better one than the original interactive model. The "boosted-fix 1.0 race model" assumed the presence of a similar top-down process, but which boosted the STOP activation instead of blocking the GO activation. It produced as good a fit to the data as the "blocked input 2.0 race model." Further neurophysiological experimentation will show if such a hypothesized top-down signal that blocks the GO activation and/or boosts the STOP activation really exists and what mechanisms allow it to switch modes of operation. 


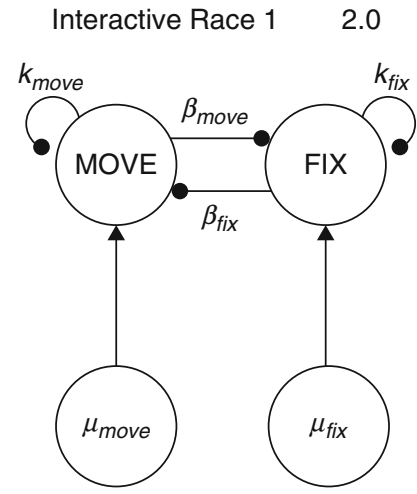

Blocked Input Model 2.0

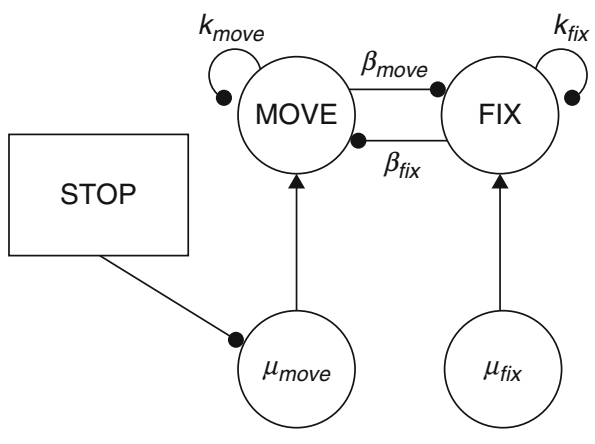

Decision Making, Countermanding Oculomotor Models, Fig. 8 Architecture of Interactive Race Model 2.0 (top left), Blocked Input Model 1.0 (top right), Blocked Input Model 2.0 (bottom left), Boosted Fixation Model 1.0

\section{Cross-References}

- Accumulation of Evidence in Decision-Making

$\checkmark$ Choice Behavior

- Decision-Making, Antisaccade Models of

- Decision-Making, Bias

- Decision-Making, Models

- Decision-Making, Threshold

D Decision-Making: Overview

> Perceptual Decision-Making

- Speed-Accuracy Tradeoff

\section{References}

Akerfelt A, Colonius H, Diederich A (2006) Visual-tactile saccadic inhibition. Exp Brain Res 169(4):554-563

Armstrong IT, Munoz DP (2003) Inhibitory control of eye movements during oculomotor countermanding in adults with attention-deficit hyperactivity disorder. Exp Brain Res 152(4):444-452
Blocked Input Model 1.0

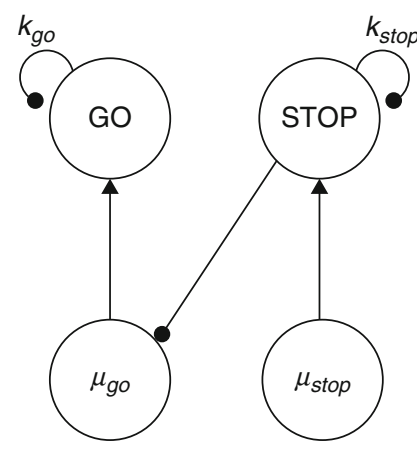

Boosted Fixation Model 1.0

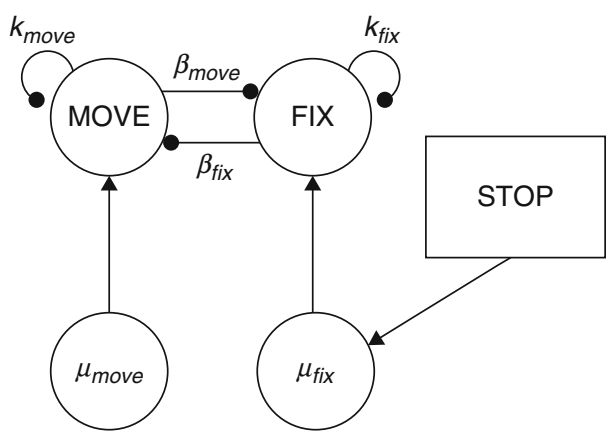

(bottom right). (Reproduced with permission from Logan et al. (2015), Figs. 8 and 9, Copyright (C), American Psychological Association)

Asrress KN, Carpenter RHS (2001) Saccadic countermanding: a comparison of central and peripheral stop signals. Vis Res 41:2645-2651

Bissett PG (2013) The countermanding task revisited: mimicry of race models. $J$ Neurosci 33(30):12150-12151

Boucher L, Palmieri TJ, Logan GD, Schall JD (2007) Inhibitory control in mind and brain: an interactive race model of countermanding saccades. Psychol Rev 114:376-397

Bruce CJ, Goldberg ME (1985) Primate frontal eye fields: I. Single neurons discharging before saccades. J Neurophys 53:603-635

Bruce CJ, Goldberg ME, Bushnell C, Stanton GB (1985) Primate frontal eye fields: II. Physiological and anatomical correlates of electrically evoked eye movements. J Neurophysiol 54:714-734

Cabel DW, Armstrong IT, Reingold E, Munoz DP (2000) Control of saccade initiation in a countermanding task using visual and auditory stop signals. Exp Brain Res 133(4):431-441

Cutsuridis V (2017) Behavioral and computational varieties of response inhibition in eye movements. Phil Trans R Soc B 372:20160196 
Everling S, Munoz DP (2000) Neuronal correlates for preparatory set associated with pro-saccades and antisaccades in the primate frontal eye field. J Neurosci 20(1):387-400

Everling S, Dorris MC, Klein RM, Munoz DP (1999) Role of primate superior colliculus in preparation and execution of anti-saccades and pro-saccades. J Neurosci 19:2740-2754

Farooqui AA, Bhutani N, Kulashekhar S, Behari M, Goel V, Murthy A (2011) Impaired conflict monitoring in Parkinson's disease patients during an oculomotor redirect task. Exp Brain Res 208(1):1-10. https://doi. org/10.1007/s00221-010-2432-y

Gandhi NJ, Keller EL (1999) Activity of the brain stem omnipause neurons during saccades perturbed by stimulation of the primate superior colliculus. J Neurophysiol 82:3254-3267

Hanes DP, Carpenter RH (1999) Countermanding saccades in humans. Vis Res 39(16):2777-2791

Hanes DP, Schall JD (1996) Neural control of voluntary movement initiation. Science 274:427-430

Hanes DP, Patterson WF, Schall JD (1998) Role of frontal eye fields in countermanding saccades: visual, movement, and fixation activity. J Neurophysiol 79(2):817-834

Hanisch C, Radach R, Holtkamp K, Herpertz-Dahlmann B, Konrad K (2006) Oculomotor inhibition in children with and without attention-deficit hyperactivity disorder (adhd). J Neural Transm 113(5):671-684

Isoda M, Hikosaka O (2007) Switching from automatic to controlled action by monkey medial frontal cortex. Nat Neurosci 10:240-248

Isoda M, Hikosaka O (2008) A neural correlate of motivational conflict in the superior colliculus of the macaque. J Neurophysiol 100(3):1332-42

Lo CC, Boucher L, Pare M, Schall JD, Wang XJ (2009) Proactive inhibitory control and attractor dynamics in countermanding action: a spiking neural circuit model. J Neurosci 29(28):9059-9071

Logan GD, Cowan WB (1984) On the ability to inhibit thought and action: a theory of an act of control. Psychol Rev 91:295-327

Logan GD, Yamaguchi M, Schall JD, Palmeri TJ (2015) Inhibitory control in mind and brain 2.0: blocked-input models of saccadic countermanding. Psychol Rev 122(2):115-147

Montagnini A, Chelazzi L (2009) Dynamic interaction between "Go" and "Stop" signals in the saccadic eye movement system: new evidence against the functional independence of the underlying neural mechanisms.
Vis Res 49(10):1316-1328. https://doi.org/10.1016/j. visres.2008.07.018

Morein-Zamir S, Kingstone A (2006) Fixation offset and stop signal intensity effects on saccadic countermanding: a crossmodal investigation. Exp Brain Res 175(3):453-462

Munoz D, Wurtz R (1993) Fixation cells in monkey superior colliculus. I. Characteristics of cell discharge. J Neurophysiol 70:559-575

Munoz D, Wurtz R (1995a) Saccade related activity in monkey superior colliculus. I. Characteristics of burst and buildup cells. J Neurophysiol 73:2313-2333

Munoz D, Wurtz R (1995b) Saccade related activity in monkey superior colliculus. II. Spread of activity during saccades. J Neurophysiol 73:2334-2348

Noorani I (2014) LATER models of neural decision behavior in choice tasks. Front Integr Neurosci 8:67

Pare M, Hanes DP (2003) Controlled movement processing: superior colliculus activity associated with countermanded saccades. J Neurosci 23:6480-6489

Salinas E, Stanford TR (2013) The countermanding task revisited: fast stimulus detection is a key determinant of psychophysical performance. J Neurosci 33(13):5668-5685

Scangos KW, Stuphorn V (2010) Medial frontal cortex motivates but does not control movement initiation in the countermanding task. J Neurophysiol 30:1968-1982

Schall JD, Godlove DC (2012) Current advances and pressing problems in studies of stopping. Curr Opin Neurobiol 22:1012-1021

Schall JD, Thompson KG (1999) Neural selection and controls of visually guided eye movements. Ann Rev Neurosci 22:241-259

Segraves MA (1992) Activity of monkey frontal eye field neurons projecting to oculomotor regions of the pons. J Neurophysiol 68:1967-1985

Segraves MA, Goldberg ME (1987) Functional properties of corticotectal neurons in the monkey's frontal eye field. J Neurophysiol 58:1387-1419

Shankar S, Massoglia DP, Zhu D, Costello MG, Stanford TR, Salinas E (2011) Tracking the temporal evolution of a perceptual judgment using a compelled-response task. J Neurosci 31(23):8406-8421

Sommer MA, Wurtz RH (2000) Composition and topographic organization of signals sent from the frontal eye field to the superior colliculus. J Neurophysiol 83:1979-2001

Stevenson SA, Elsley JK, Corneil BD (2009) A "gap effect" on stop signal reaction times in 
a human saccadic countermanding task. J Neurophysiol 101(2):580-590. https://doi.org/ 10.1152/jn.90891.2008

Stuphorn V, Taylor TL, Schall LD (2000) Performance monitoring by the supplementary eye field. Nature 408:857-860

Thakkar KN, Schall JD, Boucher L, Logan GD, Park S (2011) Response inhibition and response monitoring in a saccadic countermanding task in schizophrenia. Biol Psychiatry 69(1):55-62. https://doi.org/10.1016/ j.biopsych.2010.08.016

Thakkar KN, Schall JD, Logan GD, Park S (2015) Cognitive control of gaze in bipolar disorder and schizophrenia. Psychiatry Res 225(3):254-262. https://doi.org/10.1016/j.psychres.2014.12.033

Verbruggen F, Logan GD (2009) Models of response inhibition in the stop-signal and stop-change paradigms. Neurosci Biobehav Rev 33(5):647-661

Wattiez N, Poitou T, Rivaud-Péchoux S, Pouget P (2016) Evidence for spatial tuning of movement inhibition. Exp Brain Res 234(7):1957-1966. https://doi.org/ 10.1007/s00221-016-4594-8
Wong-Lin KF, Eckhoff P, Holmes P, Cohen JD (2010) Optimal performance in a countermanding saccade task. Brain Res 1318:178-187

\section{Further Reading}

\section{Scholarpedia}

Human saccadic eye movements. http://www. scholarpedia.org/article/Human_saccadic_eye movements

Frontal eye fields. http://www.scholarpedia.org/article/ Frontal_eye_field

\section{Wikipedia}

Antisaccade task. https://en.wikipedia.org/wiki/Anti saccade task

Two alternative forced choice. https:/en.wikipedia.org/ wiki/Two-alternative_forced_choice 